\title{
Magnitude and factors associated with appropriate complementary feeding among children 6-23 months in Northern Ghana
}

\author{
Mahama Saaka ${ }^{1 *}$, Asamoah Larbi $^{2}$, Sofo Mutaru ${ }^{3}$ and Irmgard Hoeschle-Zeledon ${ }^{4}$
}

\begin{abstract}
Background: Inappropriate complementary feeding is a major contributor to child malnutrition. Previous studies have described complementary feeding practice using single indicators but a combination of indicators is needed to better explain the role of complementary feeding practices in child growth. To adequately quantify appropriate complementary feeding, we used a composite indicator comprising three of the World Health Organization (WHO) core infant and young child feeding (IYCF) indicators that relate closely to complementary feeding.
\end{abstract}

Methods: A community-based cross sectional cluster survey was carried out in November 2013. The study population comprised mothers/primary caregivers and their children selected using a two-stage cluster sampling procedure. A total of 778 children aged 6-23 months were involved.

Results: Of the children aged 6-23 months; $57.3 \%$ met the minimum meal frequency, $35.3 \%$ received minimum dietary diversity ( $\geq 4$ food groups), $25.2 \%$ had received minimum acceptable diet and only $14.3 \%$ received appropriate complementary feeding.

Multivariable logistic regression adjusted for cluster sampling showed that children aged 12-23 months were 26.6 times more likely [AOR 26.57; $95 \% \mathrm{Cl}(3.66-193.12)]$ to receive appropriate complementary feeding compared to children aged 6-8 months. Children who were not bottled-fed were 2.5 times more likely to have been appropriately fed [AOR 2.51; $95 \% \mathrm{Cl}(1.98-6.42)]$ compared to children who were bottle-fed in the last $24 \mathrm{~h}$ prior to study.

Conclusions: Findings from this study demonstrate appropriate complementary feeding and caring practices by caregivers remain a challenge for most households in Northern Ghana.

Keywords: Appropriate complementary feeding, Dietary diversity, Meal frequency, Acceptable diet, Northern Ghana

\section{Background}

Childhood malnutrition remains one of the most intractable public health problems throughout the developing world including Ghana. The estimated prevalence of chronic malnutrition for example, in Northern Region is $33.1 \%$ compared with a national average of $19 \%$ [1]. Variation in the prevalence of acute malnutrition among children across regions exists, ranging from a low of 3 to $9 \%$. Similarly, according to the survey, $66 \%$ of children

\footnotetext{
* Correspondence: mmsaaka@gmail.com

${ }^{1}$ University for Development Studies, School of Allied Health Sciences, P O Box 1883, Tamale, Ghana

Full list of author information is available at the end of the article
}

aged 6-59 months in Ghana have some level of anaemia $(\mathrm{Hb}<11 \mathrm{~g} / \mathrm{dL})$ but anaemia in children is most common in Northern region with a prevalence of $82 \%$.

There are several determinants of under-nutrition, including poor dietary practices, non-availability of food and high rates of infection but these factors vary depending on geographic, social, and cultural settings. Mostly however, a major drawback on being fed an adequate diet is lack of access to diversified foods and insufficient meal frequency after 6 months of age $[2,3]$. About $6 \%$ of under-five deaths can be prevented particularly in the developing world if optimal complementary feeding is ensured, thereby contributing towards the 
realization of the Millennium Development Goal four [4-6]. Complementary feeding is defined as giving children other foods or fluids in addition to the breast milk at six months age of child [7].

The World Health Organization (WHO) has developed eight core infant and young child feeding indicators to monitor and to guide the feeding practices of young children $[8,9]$ including the following: (1) early initiation of breastfeeding; (2) exclusive breastfeeding under six months; (3) continued breastfeeding for one year; (4) the introduction of solid, semi-solid or soft foods; (5) minimum dietary diversity; (6) minimum meal frequency; (7) minimum acceptable diet; and (8) consumption of iron rich or iron fortified foods.

The development of successful interventions to improve child-feeding practices, in particular, requires appropriate instruments that can adequately assess current feeding practices and monitor the impact of programmes designed to improve them [10]. Therefore, knowledge of the magnitude and predictors of appropriate complementary feeding practices is an important step in designing and evaluating appropriate interventions that seek to address poor infant and young child feeding practices. However, there is little information on the extent mothers adhere to the WHO recommended infant and young child feeding practices in Northern Ghana. Furthermore, given the strong links between diet diversity and nutritional outcomes [11-14], this study sought to assess the prevalence of appropriate complementary feeding practices and its determinants among children aged 6-23 months who reside in rural areas of Northern Ghana where child malnutrition is a serious concern.

\section{Methods}

\section{Study area}

The nutrition survey covered five programme districts of Northern Ghana comprising the Northern Region (NR), Upper East Region (UER) and Upper West Region (UWR). The five districts where International Institute of Tropical Agriculture (IITA) project is currently operating are Nadowli, Wa West, Tolon, Savelugu and Kassena-Nankana.

Majority of the people in the study area have agriculture as their main occupation while some are involved in trading. The main staple foods including maize, sorghum, millet and yam are usually harvested from October through December. Although the food security situation is usually good during the harvesting time, child care tends to suffer because of lack of time on the part of rural mothers. A high proportion of rural women work daily away from home, and therefore frequently face challenges to the care of children.

The rainfall pattern is unimodal and the period is usually short and lasts from May to August, followed by a long dry season (September - April) with dry harmattan winds.

\section{Survey design, population and sampling}

This paper is based on re-analysis of data which was collected in a base-line cross-sectional survey in November 2013. The overall aim of the community based crosssectional study was to collect information on knowledge and practices related to infant and young child feeding (IYCF) practices which will serve as a baseline for future comparison after the implementation of IITA sponsored nutrition project.

A sample size of 288 was required to ensure that the estimated prevalence of the main outcome variable was within plus or minus $5 \%$ of the true prevalence at $95 \%$ confidence level. Assuming a correction factor of 2 (the "design effect") for cluster sampling, the sample size was increased to 576. A non response rate of $5 \%$ and other unexpected events (e.g., damaged/incomplete questionnaire) was factored in the sample size determination and so the sample size is adjusted to 600 for 25 intervention communities that were already selected. The same number of children was selected from comparison communities using probability proportionate to size (PPS).

The basic primary sampling unit was the household and these were selected using a two-stage cluster sampling technique. PPS was used to select the comparison communities in adjacent districts given the lack of a comprehensive sampling frame and the geographic distribution of the population. Each comparison district was considered a stratum, from which clusters were selected based on stratified probability proportional to population size (PPS) sampling. The sampling frame of communities for each district was constructed using projected population figures based on 2010 Ghana population census. The Emergency Nutrition Assessment (ENA) software was used to randomly select the required number of clusters.

In each selected cluster, a complete list of all households was compiled, and systematic random sampling was used to select eligible households.

\section{Data collection}

Data were collected using face-to-face interview during house-to-house visit from mothers who had 6-36 months age children using structured questionnaire. The mother of the child or other caretaker provided information on the child's age, gender, morbidity in the past week and child feeding practices. Information on the household's composition, household wealth index (socioeconomic), crop and poultry/livestock production practices and child anthropometry indicators were also collected. 


\section{Independent and dependent variables}

The main outcome variable for this study was the prevalence of appropriate complementary feeding and its components. The independent variables were maternal, child and household characteristics. A brief description of main independent and dependent variables is as follows:

\section{Assessment of infant and young child feeding (IYCF) practices}

Infant and young child feeding indicators including minimum meal frequency, minimum dietary diversity and minimum acceptable diet were estimated by recall of food and liquid consumption during the previous day of the survey as per WHO/UNICEF guidelines [15].

A child was judged to have taken 'adequate number of meals if he/she received the minimum frequency for appropriate complementary feeding (that is, 2 times for 6-8 months and 3 times for 9-11 months, 3 times for children aged 12-23 months) in last $24 \mathrm{~h}$. For non breast feeding children, the minimum meal frequency was 4 . Adequacy of meal frequency was ranked by assigning a score of 1 .

The WHO defined minimum dietary diversity as the proportion of children aged 6-23 months who received foods from at least four out of seven food groups $[8,9]$. The 7 foods groups used for calculation of WHO minimum dietary diversity indicator are:

(i) grains, roots and tubers; (ii) legumes and nuts; (iii) dairy products; (iv) flesh foods; (v) eggs; (vi) vitamin A rich fruits and vegetables; and (vii) other fruits and vegetables.

From the dietary diversity score, the minimum dietary diversity indicator was constructed using the WHO recommended cut-off point with a value of " 1 " if the child had consumed four or more groups of foods and " 0 " if less. Minimum dietary diversity is the proportion of children who ate at least 4 or more varieties of foods from the seven food groups in a $24 \mathrm{~h}$ time period [8, 9]. Minimum acceptable diet is a composite indicator of minimum dietary diversity and minimum meal frequency. Breastfed children who meets both the minimum diversity and the minimum meal frequency are considered to have met the WHO recommended minimum acceptable diet.

Previous studies have described complementary feeding practices using single indicators but a combination of indicators is needed to better explain the role of complementary feeding practices in child growth. To adequately quantify appropriate complementary feeding, we used a composite indicator comprising three of the WHO core IYCF indicators that relate closely to complementary feeding. These are timely introduction of solid, semi-solid or soft foods at 6 months, minimum meal frequency, and minimum dietary diversity. In this study, a child was classified as having received appropriate complementary feeding if the child met all the following three criteria:

i. Complementary feeding commenced at 6th month of birth

ii. Minimum dietary diversity score was at least 4

iii. Minimum meal frequency was adequate for age of child

Complementary feeding was inappropriate if any of the three criteria was not fulfilled

\section{Malnutrition classification}

For the present study, we defined positive deviant children as having both height - for -age Z-score (HAZ) and weight - for height Z-score (WHZ) $\geq-2$ (best nutritional status). A negative deviant child was defined as having both $\mathrm{HAZ}$ and $\mathrm{WHZ}<-2$. Median deviant child was defined as having either $\mathrm{HAZ}$ or $\mathrm{WHZ}<-2$.

\section{Statistical data analyses}

Both bivariate and multivariate analyses were done to identify the determinants of appropriate feeding practices and minimum dietary diversity (MDD). Firstly, bivariate analyses for all the various risk factors were performed using $X^{2}$ tests. Child, maternal and household characteristics that were significantly associated with the outcome variable were included in the logistic regression (LR) models. Multiple logistic regression analyses using appropriate measures to account for the complex survey design were applied to examine the associations between dependent variable (that is, appropriate complementary feeding) and potential predictors. Stepwise backward LR was used for multiple logistic regressions. Odds ratio with $95 \%$ confidence interval to ascertain association between independent and dependent variable was used.

\section{Ethics consideration}

The study protocol was approved by the Ethical Committee of the School of Allied Health Sciences, University for Development Studies. Community leaders in the study communities were briefed about the study and permission sought to proceed. Informed consent was also obtained verbally after needed information and explanation. Participation was voluntary and each woman signed (or provided a thumb print if she was illiterate) a statement of an informed consent after which she was interviewed.

\section{Results}

\section{Sample characteristics}

Table 1 presents the summary statistics on key characteristics of mother - child pairs in our sample. The study sample comprised a total of 778 children aged 6-23 months with the majority of their mothers $(69.8 \%)$ had 
Table 1 Sample characteristics

\begin{tabular}{lll}
\hline Characteristics & Frequency (n) & Percentage (\%) \\
\hline Religion of respondent & 360 & 46.3 \\
Christianity & 375 & 48.2 \\
Islam & 35 & 4.5 \\
African traditional religion (ATR) & 8 & 1.0 \\
Other & & \\
Marital status & 11 & 1.4 \\
Single & 762 & 97.9 \\
Married & 3 & 0.4 \\
Widow & 2 & 0.3 \\
Separated & & \\
Educational level of mothers & 543 & 69.8 \\
None & 115 & 14.8 \\
Primary & 101 & 13.0 \\
Junior High School (JHS) & 18 & 2.3 \\
Senior High School (SHS) & 1 & 0.1 \\
Tertiary & & 13.2 \\
Age Groups of mothers (years) & 11 & \\
Under 18 & 664 & 1.4 \\
18-35 & 103 & \\
More than 35 & & \\
\hline
\end{tabular}

no formal education. The mean age of the respondents was $28.3 \pm 6.5$ years with the minimum and maximum ages of 15 and 52 years respectively. The sample comprised $63.6 \%$ of children aged $12-23$ months.

\section{Nutritional status and dietary intake of children aged 6-23 months}

With respect to nutritional status of children aged 6-23 months, $16.1 \%$ (CI: 13.5 to 19.2 ), $19.2 \%$ (CI: 15.5 to 23.6) and $23.1 \%$ (CI: 19.2 to 27.5 ) of the study population were wasted, stunted, and underweight respectively. The proportion of children 6-23 months who met the minimum dietary diversity ( $\geq 4$ food groups) was 35.6 and $57.3 \%$ had adequate meal frequency. Only $24.9 \%$ of the children aged 6-23 months met the minimum acceptable diet. Children who met the acceptable diet and started complementary feeding at six months were considered to have appropriate complementary feeding. Therefore the overall appropriate complementary prevalence was only $13.8 \%$ (Table 2 ).

\section{Factors found associated with appropriate complementary feeding practice}

In bivariate analysis, place of residence, age of the child, religion of mother, avoidance of bottle feeding, timely initiation of breast feeding and absence of diarrhoeal
Table 2 Nutritional status and dietary intake of children aged 6-23 months

\begin{tabular}{|c|c|c|c|}
\hline Characteristics & Mean \pm SD & $\begin{array}{l}\text { Frequency } \\
\text { (n) }\end{array}$ & $\begin{array}{l}\text { Percentage } \\
(\%)\end{array}$ \\
\hline \multicolumn{4}{|l|}{ Nutritional status } \\
\hline WAZ & $-1.13 \pm 1.1$ & & \\
\hline HAZ & $-0.88 \pm 1.35$ & & \\
\hline WHZ & $-0.91 \pm 1.13$ & & \\
\hline Stunted $(H A Z<-2)$ & & 130 & 16.8 \\
\hline Wasted $(\mathrm{WHZ}<-2)$ & & 116 & 15.0 \\
\hline Underweight (WAZ <-2) & & 163 & 21.0 \\
\hline $\begin{array}{l}\text { Diarrhoeal infection the past } \\
14 \text { days }\end{array}$ & & 284 & 36.5 \\
\hline Currently breastfeeding & & 759 & 97.6 \\
\hline Prevalence of bottle feeding & & 87 & 11.2 \\
\hline $\begin{array}{l}\text { Met minimum meal } \\
\text { frequency }\end{array}$ & & 431 & 57.3 \\
\hline $\begin{array}{l}\text { Met minimum dietary } \\
\text { diversity }\end{array}$ & & 276 & 35.6 \\
\hline $\begin{array}{l}\text { Met minimum acceptable } \\
\text { diet }\end{array}$ & & 193 & 24.9 \\
\hline $\begin{array}{l}\text { Appropriate complementary } \\
\text { feeding rate }\end{array}$ & & 107 & 13.8 \\
\hline
\end{tabular}

infection were positively associate with appropriate complementary (Tables 3 and 4).

Multiple logistic regressions analysis showed three variables were significantly associated with appropriate complementary feeding practice. These were child's age, absence of illness and whether the child was classified as positive, median or negative deviants.

Compared with positive deviants, negative deviants were 2.7 times more likely to be fed appropriately [AOR 2.74; 95 \% CI (1.12-6.71)]. In terms of appropriate complementary feeding, there was no difference between positive deviants and median growers. Younger children were less likely to be fed appropriately, compared with older children. Compared to children aged 6-8 months, older children aged 9-23 months were 14 times more likely to meet recommended complementary feeding practices [AOR 14.09; $95 \%$ CI (1.87-106.30)].

Compared to children who were reported sick from diarrhoea at any time in the last two weeks, children who were well were 1.8 times more likely to receive appropriate complementary feeding [AOR 14.09; $95 \%$ CI (1.87-106.30)] (Table 5).

\section{Discussion}

This study sought to quantify appropriate complementary feeding using a composite indicator comprising three of the WHO recommended core IYCF indicators. It also investigated factors that are associated with appropriate complementary feeding. 
Table 3 Factors associated with appropriate complementary feeding practice among children aged 6-23 months (Bivariate analysis)

\begin{tabular}{|c|c|c|c|c|}
\hline \multirow[t]{2}{*}{ Characteristic } & \multirow[t]{2}{*}{ N } & \multicolumn{2}{|c|}{ Complementary feeding practice } & \multirow[b]{2}{*}{ Test statistic } \\
\hline & & Inappropriate n (\%) & Appropriate n (\%) & \\
\hline \multicolumn{5}{|l|}{ Region of residence } \\
\hline Northern & 311 & $280(90.0)$ & $31(10.0)$ & \multirow[t]{3}{*}{$x^{2}=6.9 p=0.03$} \\
\hline Upper East & 156 & $133(85.3)$ & $23(14.7)$ & \\
\hline Upper West & 308 & $255(82.8)$ & $53(17.2)$ & \\
\hline \multicolumn{5}{|l|}{ Age of child (months) } \\
\hline $6-11$ & 285 & $265(93.0)$ & $20(7.0)$ & \multirow[t]{3}{*}{$x^{2}=19.9 p<0.001$} \\
\hline $12-17$ & 242 & $205(84.7)$ & $37(15.3)$ & \\
\hline $18-23$ & 248 & $198(79.8)$ & $50(20.2)$ & \\
\hline \multicolumn{5}{|l|}{ Religion of mother } \\
\hline Christianity & 360 & $298(82.8)$ & $62(17.2)$ & \multirow[t]{3}{*}{ Fisher's exact test $=6.4 p=0.04$} \\
\hline Islam & 372 & $331(89.0)$ & $41(11.0)$ & \\
\hline African Traditional Religion (ATR) & 43 & $39(90.7)$ & $4(9.3)$ & \\
\hline
\end{tabular}

Due to the multidimensional nature of feeding practices, which is also age-specific [16], an appropriate tool to determine the overall child-feeding practices is yet to be determined. Minimum dietary diversity, adequacy of meal frequency and timely initiation of complementary feeding were the WHO indicators factors used in building the composite index and this study is the first of its kind in which important WHO IYCF indicators were combined to quantify appropriate complementary feeding in Northern Ghana. This composite index reflects key components of child feeding, namely appropriate timing of introduction of complementary foods, dietary density and adequacy of meal frequency.

The results revealed that the prevalence of appropriate complementary feeding was only $13.8 \%$ which is similar

Table 4 Factors associated with appropriate complementary feeding practice among children aged 6-23 months (Bivariate analysis)

\begin{tabular}{|c|c|c|c|c|}
\hline \multirow[t]{2}{*}{ Characteristic } & \multirow[t]{2}{*}{$\mathrm{N}$} & \multicolumn{2}{|c|}{ Complementary feeding practice } & \multirow[b]{2}{*}{ Test statistic } \\
\hline & & Inappropriate & Appropriate & \\
\hline \multicolumn{5}{|c|}{ Timely initiation of breast feeding } \\
\hline No & 414 & $366(88.4)$ & 48 (11.6) & \multirow[t]{2}{*}{$x^{2}=3.6, p=0.06$} \\
\hline Yes & 361 & $302(83.7)$ & $59(16.3)$ & \\
\hline \multicolumn{5}{|c|}{ Child had diarrhoea in the last two weeks? } \\
\hline Yes & 283 & $253(89.4)$ & $30(10.6)$ & \multirow[t]{2}{*}{$x^{2}=3.8, p=0.05$} \\
\hline No & 492 & $415(84.3)$ & $77(15.7)$ & \\
\hline \multicolumn{5}{|l|}{ Bottle feeding } \\
\hline Yes & 86 & $81(94.2)$ & $5(5.8)$ & \multirow[t]{2}{*}{$x^{2}=5.2, p=0.02$} \\
\hline No & 689 & $587(85.2)$ & $102(14.8)$ & \\
\hline \multicolumn{5}{|c|}{ Currently breastfeeding? } \\
\hline No & 19 & $13(68.4)$ & $6(31.6)$ & \multirow[t]{2}{*}{$x^{2}=5.2, p=0.02$} \\
\hline Yes & 756 & $655(86.6)$ & $101(13.4)$ & \\
\hline
\end{tabular}

to what was reported from Northern Ethiopia, Sri Lanka, Nepal and Tanzania Bangladesh, Zambia, and [17-20]. This indicates the general low level of appropriate complementary feeding practices in many countries including Ghana.

The three consistent variables that were found to be significantly associated with appropriate complementary feeding practice in this study were increasing child's age, freedom from illness and whether the child was classified as positive, median or negative deviants. Other variables that were significant in bivariate analysis but failed to reach significance level in the multivariate analysis were region of residence, bottle feeding, religion of mother, timely initiation of breast feeding and absence of diarrhoeal infection.

Children within the age group 9-23 months were 14 times more likely to be appropriately fed as compared to infants in the age group 6-8 months. This finding is congruent with the findings in many countries including Ethiopia, Zambia Nepal, Indonesia and Tanzania where older children are more likely to be fed on complementary foods optimally [17, 20-22]. Education on complementary feeding should therefore target mothers of young children to give such children diversified diets that also meet adequate meal frequency. The 6-8 months age period is known to coincide with the period of the fastest growth faltering [23]. Poor complementary feeding practices in this age group should therefore be addressed effectively in order to greatly reduce the risk of growth faltering.

One would expect that positive deviant children will receive better appropriate feeding. Surprisingly, more of the negative deviant children (29.6\%) received appropriate complementary feeding compared to median growers (13.5\%) and positive deviants (13.2\%). The inverse 
Table 5 Determinants of appropriate complementary feeding practices

\begin{tabular}{lllll}
\hline Variable & Wald & Sig.) & & $\begin{array}{l}95 \% \text { confidence Interval } \\
(\mathrm{Cl}) \\
\text { Lower }\end{array}$ \\
& & & $\begin{array}{l}\text { Adjusted odds ratio } \\
\text { (AOR) }\end{array}$ & 1.16 \\
\hline $\begin{array}{l}\text { Free from diarrhoea in the past two } \\
\text { weeks }\end{array}$ & 6.78 & 0.009 & 1.83 & 1.03 \\
Height of the child & 10.11 & 0.001 & 1.07 & \\
Deviance (reference: positive deviants) & 4.88 & 0.09 & & .649 \\
Median growers & 0.07 & 0.79 & 1.071 & 1.12 \\
$\quad$ Negative deviants & 4.87 & 0.03 & 2.74 & 1.87 \\
$\quad$ Age group (9-23 months) & 6.59 & 0.01 & 14.09 & 1.12 \\
Constant & 30.39 & $<0.001$ & .000 & 1.768 \\
\hline
\end{tabular}

relationship was more pronounced with respect to acceptable diet whereby $51.9 \%$ of negative deviants, $26.6 \%$ of median growers and $23.2 \%$ met the criterion for acceptable diet. The issue of reverse causality may be applicable here whereby the sick child is given better care with regards to appropriate complementary feeding. This means, the undernutrition gives the mother the opportunity to provide appropriate complementary feeding.

Our data also showed that children with diarrhoeal infection were less likely to be fed appropriately. The negative association between sickness and appropriate complementary feeding is for the fact that some mothers would avoid feeding or reduce the meal frequency during diarrhoeal episode of the child and this will be detrimental to appropriate complementary feeding as defined in this study. Mothers should be educated and encouraged to continue to feed their children even when they have diarrhoea.

This study revealed that there was no association between frequency of antenatal care (ANC) visits and appropriate complementary feeding practice and same was reported in Northern Ethiopia [17] but that disagrees with other studies in Nepal, India and Sri Lanka [18, 19, 24] where inadequate antenatal care was associated with inappropriate complementary feeding. The finding in our study could imply that appropriate complementary feeding messages were either not being given to mothers by health professionals during antenatal or there was little variation in ANC attendance among the mothers. Most of the mothers (84.2\%) actually made at least four visits during the last pregnancy. Similarly, maternal educational level and socio-economic status as measured by household wealth index were also not associated with complementary feeding practices in this study. The lack of association may be attributed to the little variation of these variables in our study sample. In other studies, higher maternal education attainment is reported to associate positively with appropriate complementary feeding $[19,20]$

Geographic location was also an important determinant of appropriate complementary feeding. Children from the
Upper West and Upper East Regions were more likely to receive appropriate complementary feeding when compared to the children from Northern Region. The regional differentials in complementary feeding practices strongly suggest the importance of ensuring that interventions to improve complementary feeding are evidence-based and are informed by context specific formative research.

As expected, higher household wealth significantly increases diet diversity. Household wealth index positively associated with a higher dietary diversity score (DDS). Rich families are more likely to be able to afford and provide a variety of foods to their children more frequently. The positive association between higher household wealth and increased diet diversity has been consistently reported in earlier studies in different countries including Bangladesh, India, Nepal, Pakistan and Sri Lanka [25-27]. The fact that household wealth is a predictor of minimum dietary diversity underlines the important role of household resources in determining optimal complementary feeding practices.

Families that reported keeping chickens, ducks, or other birds for the meat/sale were more likely to provide children with diversified foods. Initial studies show a strong positive relationship between biodiversity in agricultural production and improved diversified diets [28]. Therefore, an appropriate mix of behaviour change communication and production of local food varieties and poultry resources could be a feasible option to increase recommended infant feeding practices and reduce under nutrition. Educational interventions can be implemented through existing mother's group meetings, community health volunteers, and outreach clinics including primary health care outreach clinics will help promote good child feeding practices.

\section{Conclusion}

In conclusion, the overall prevalence of appropriate complementary feeding practices was very low, an indication that appropriate complementary feeding by caregivers remains a challenge for most households in 
Northern Ghana. Focused behaviour change communication strategies should therefore target care-givers to provide diversified complementary foods timely to their children at six months of age.

The results presented in this study highlight the fact that both the magnitude and determinants of appropriate complementary feeding vary depending on what indicator or set of indicators are used. Furthermore, the findings underscore the need to always have context specific information in designing and evaluating appropriate interventions that seek to address poor infant and young child feeding practices. This is because factors that determine feeding practices are never the same in every environment and especially so when different indicators are used in measuring them.

\section{Study limitations}

Like any other observational studies, this study has some limitations. The cross sectional nature of the study prevents it from making causal inference. The information collected was mainly through interviews. There is possibility that some of the responses might suffer from recall bias and this may affect prevalence estimates. Also the complex nature of complementary feeding makes some aspects of it more difficult to capture and accurately assess.

\section{Competing interests}

The authors declare that they have no competing interests.

\section{Authors' contributions}

MS and SM designed the study, analyzed and interpreted the data. MS drafted the manuscript. AL and I $\mathrm{H}$ revised it critically for important intellectual content. SM assisted with the development of the questionnaire and data collection from the field. All authors read and approved the final manuscript.

\section{Acknowledgements}

The authors would like to gratefully acknowledge funding received from IITA Africa RISING Project under the USAID Feed the Future Nutrition. We are thankful to the data collection team members from the Ghana Health Service (GHS) for their hard work and commitment. The data could not have been obtained without the co-operation and support of the programme communities, especially the mothers and caregivers who took time off from their busy schedules to respond to the interviewers. Their involvement and cooperation is highly appreciated.

\section{Funding}

The study was funded by IITA Africa RISING Project under the USAID Feed the Future Nutrition.

\footnotetext{
Author details

${ }^{1}$ University for Development Studies, School of Allied Health Sciences, P O Box 1883, Tamale, Ghana. ${ }^{2}$ International Institute of Tropical Agriculture (IITA) P O Box 6, Tamale, Ghana. ${ }^{3}$ Ghana Health Service, Tamale, Northern Region, Ghana. ${ }^{4}$ International Institute of Tropical Agriculture (IITA), PMB 5320, Oyo Road, Ibadan, Nigeria.
}

Received: 28 May 2015 Accepted: 8 December 2015 Published online: 09 January 2016

\section{References}

1. Ghana Statistical Service (GSS), Ghana Health Service (GHS), ICF International. Ghana Demographic and Health Survey 2014. Rockville: GSS, GHS, and ICF International; 2015.

2. Pan American Health Organization, World Health Organization. Guiding Principles for Complementary Feeding of the Breastfed Child. Geneva: World Health Organization; 2003.

3. Black RE, Allen LH, Bhutta ZA, Caulfield LE, de Onis M, Ezzati M, et al. Maternal and child undernutrition: global and regional exposures and health consequences. Lancet. 2008;371:243-60.

4. Black RE, Morris SS, Bryce J. Where and why are 10 million children dying every year? Lancet. 2003;361(9376):2226-34.

5. Jones G, Steketee RW, Black RE, Bhutta ZA, Morris SS, Bellagio Child Survival Study Group. How many child deaths can we prevent this year? Lancet. 2003;362:65-7.

6. Lutter C. Meeting the challenges to improve complementary feeding. Stand Committee Nutr News. 2003;27:4-9.

7. World Health Organization. Complementary Feeding: Summary of Guiding Principles. Report of the Global Consultation in 2001. Geneva: World Health Organization; 2002.

8. World Health Organization. Indicators for assessing infant and young child feeding practices Part 1 Definitions. Washington DC: World Health Organization, Dept. of Child and Adolescent Health and Development; 2007.

9. WHO, UNICEF, USAID, FANTA, AED, UC DAVIS, IFPRI. Indicators for assessing infant and young child feeding practices part 2: measurement. Geneva: The World Health Organization; 2010.

10. Ruel MT, Brown KH, Caulfield LE. Moving Forward with Complementary Feeding: Indicators and Research Priorities. In: FCND Discussion Paper No 146. Washington, D.C: Food Consumption and Nutrition Division, International Food Policy Research Institute; 2003.

11. Ruel MT, Menon P. Child feeding practices are associated with child nutritional status in Latin America: innovative uses of the demographic and health surveys. J Nutr. 2002;132:1180-7.

12. Rah JH, Akhter N, Semba RD, de Pee S, Bloem MW, Campbell AA, et al. Low dietary diversity is a predictor of child stunting in rural Bangladesh. Eur J Clin Nutr. 2010:64(12):1393-8.

13. Zongrone A, Winskell K, P. M. Infant and Young Child Feeding (IYCF) Practices and Child Undernutrition in Bangladesh: Insights from Nationally Representative. Data Pub Health Nutr. 2012, doi:10.1017/ S1368980012001073

14. Arimond M, Ruel MT. Dietary diversity is associated with child nutritional status: evidence from 11 demographic and health surveys. J Nutr. 2004; 134:2579-85

15. WHO/UNICEF/IFPRI/UCDavis/FANTA/AED/USAID. Indicators for assessing infant and young child feeding practices. Part 1: Definitions. Geneva: World Health Organization; 2008.

16. Moursi MM, Arimond M, Dewey KG, Treche S, Ruel MT, Delpeuch F. Dietary diversity is a good predictor of the micronutrient density of the diet of 6- to 23-month-old children in Madagascar. J Nutr. 2008;138(12):2448-53.

17. Mekbib E, Shumey A, Ferede S, Haile F. Magnitude and factors associated with appropriate complementary feeding among mothers having children 6-23 months-of-age in Northern Ethiopia; A Community-Based Cross-Sectional Study. J Food Nutr Sci. 2014;2(2):36.

18. Senarath U, Godakandage SS, Jayawickrama H, Siriwardena I, Dibley MJ. Determinants of inappropriate complementary feeding practices in young children in Sri Lanka: secondary data analysis of demographic and health survey 2006-2007. Matern Child Nutr. 2012;8 Suppl 1:60-77.

19. Joshi N, Agho KE, Dibley MJ, Senarath U, Tiwari K. Determinants of inappropriate complementary feeding practices in young children in Nepal: secondary data analysis of demographic and health survey 2006. Matern Child Nutr. 2012;8 Suppl 1:45-59.

20. Rose V, Baines SK, Agho KE, Dibley MJ. Factors associated with inappropriate complementary feeding practices among children aged 6-23 months in Tanzania. Matern Child Nutr. 2012;23:22925557.

21. Disha AD, Rawat R, Subandoro A, Menon P. Infant and Young Child Feeding (IYCF) Practices in Ethiopia and Zambia and their association with child nutrition: analysis of demographic and health survey data. AJFAND. 2012;12(2):5895-913

22. Charmaine SN, Dibley MJ, Agho KE. Complementary feeding indicators and determinants of poor feeding practices in Indonesia: a secondary analysis of 2007 demographic and health survey data. Food Nutr Bull. 2010;31(2):366-75. 
23. Victora CG, De OM, Hallal PC, Blossner M, Shrimpton R. Worldwide timing of growth faltering: revisiting implications for interventions. Pediatrics. 2010;125:e473-80.

24. Aggrawal A, Verma S, Feridi MA, Chand D. Complementary feeding-reasons for inappropriateness in timing, quality and consistency. Indian J Pediatr. 2008;75:49-56.

25. Bhagowalia P, Menon P, Quisumbing AR, Soundararajan V: What Dimensions of Women's Empowerment Matter Most for Child Nutrition? Evidence Using Nationally Representative Data from Bangladesh. In: IFPRI Discussion Paper 01192. IFPRI, Washington D.C; 2012.

26. Senarath U, Agho KE, Dur-e-Samin A, Godakandage SSP, Hazir T, Jayawickrama $\mathrm{H}$, et al. Comparisons of complementary feeding indicators and associated factors in children aged 6-23 months across five South Asian countries. Matern Child Nutr. 2012;8 Suppl 1:89-106.

27. Senarath U, Dibley MJ. Complementary feeding practices in South Asia: analyses of recent national survey data by the South Asia infant feeding research network. Matern Child Nutr. 2011;8 Suppl 1:5-10.

28. Bhagowalia P, Headey D, Kadiyala S. Agriculture, Income and Nutrition Linkages in India: Insights from a Nationally Representative Survey IFPRI Discussion Paper 01195. Washington DC: International Food Policy Research Institute; 2012. p. 31

\section{Submit your next manuscript to BioMed Central} and we will help you at every step:

- We accept pre-submission inquiries

- Our selector tool helps you to find the most relevant journal

- We provide round the clock customer support

- Convenient online submission

- Thorough peer review

- Inclusion in PubMed and all major indexing services

- Maximum visibility for your research

Submit your manuscript at www.biomedcentral.com/submit 